УДК 51

\author{
L. MALIGRANDA
}

\title{
REVIEW OF THE BOOK BY ROMAN DUDA, "PEARLS FROM A LOST CITY. THE LVOV SCHOOL OF MATHEMATICS"
}

\begin{abstract}
L. Maligranda. Review of the book by Roman Duda, "Pearls from a lost city. The Lvov school of mathematics", Mat. Stud. 46 (2016), 203-216.

This review is an extended version of my two short reviews of Duda's book that were published in MathSciNet and Mathematical Intelligencer. Here it is written about the Lvov School of Mathematics in greater detail, which I could not do in the short reviews. There are facts described in the book as well as some information the books lacks as, for instance, the information about the planned print in Mathematical Monographs of the second volume of Banach's book and also books by Mazur, Schauder and Tarski.
\end{abstract}

My two short reviews of Duda's book were published in MathSciNet [16] and Mathematical Intelligencer [17]. Here I write about the Lvov School of Mathematics in greater detail, which was not possible in the short reviews. I will present the facts described in the book as well as some information the books lacks as, for instance, the information about the planned print in Mathematical Monographs of the second volume of Banach's book and also books by Mazur, Schauder and Tarski. So let us start with a discussion about Duda's book.

In 1795 Poland was partioned among Austria, Russia and Prussia (Germany was not yet unified) and at the end of 1918 Poland became an independent country. This was a good period for some remarkable development of science. Great mathematical centers were created in Warsaw (with Sierpiński, Mazurkiewicz and Kuratowski), Lvov (with Banach, Steinhaus and Mazur) and Cracow (with Zaremba and Żorawski). Unfortunately, Zaremba and Żorawski worked separately, and

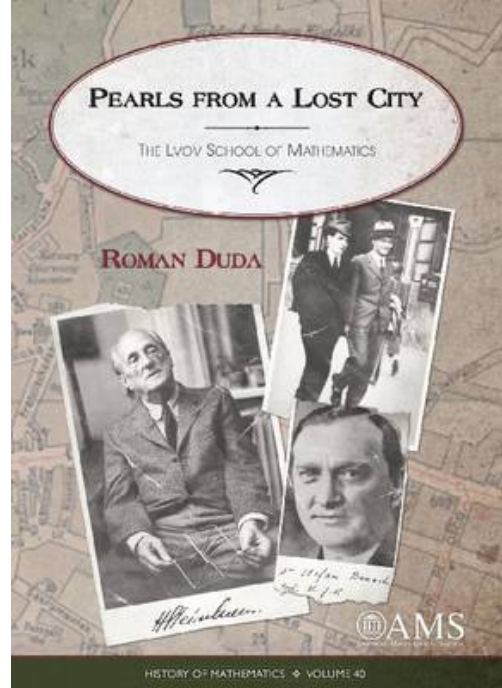

Figure 1. Front page of Duda's book no mathematical school was formed in Cracow before the World War II. They did create, however, a scientific milieu in Cracow (cf. [3] and [30, pp. 217-220]).

The Lvov School of Mathematics was a group of mathematicians in the Polish city Lvov (then Lwów), active in the period 1920-1945 under the leadership of Stefan Banach and Hugo Steinhaus who worked together, and often visited the Scottish Café (Kawiarnia Szkocka) to 
discuss mathematical problems. Without a notable mathematical tradition, the school made major contributions to what is now called functional analysis (analysis of functionals or infinite-dimensional analysis). The results and names of Banach, Kac, Kuratowski, Mazur, Orlicz, Schauder, Sierpiński, Steinhaus, and Ulam, among others, occur frequently in modern articles and textbooks.

Duda's book treats the Lvov school with the aim of identifying and describing the time and place of historical events, the key individuals and their followers, the school's greatest achievements and their significance. An attempt is also made to assess the influence of the school on mathematics in Poland as well as around the world. The book is divided into seven parts: I. Background, II. The golden age: individuals and community, III. The golden age: achievements, IV. Oblivion, V. Historical significance, VI. List of Lvov mathematicians (with 55 biographies of each of the mathematicians associated with Lvov), VII. Bibliographies. This last part has three sections: (A) Mathematical works by Lvov mathematicians; (B) Personal recollections, surveys, and historical source material; and (C) Other mathematical works cited. Each part is subdivided into chapters, of which there are 37 in total (31 numbered and 6 unnumbered).

The first five parts describe the school itself, whereas the last two provide complementary material. In the five chapters of the first part we find a short history of the University and Politechnic in Lvov, Polish mathematics at the turn of the twentieth century, discussion of the role of Sierpiński, who was at Lvov University in the period 1908-1914, the importance of Janiszewski's program at Warsaw University (1915-1920) and the state of mathematics around 1920, focusing on those areas where Polish mathematics would later distinguish itself so highly in the interwar years.

In Part II, called "The Golden Age: Individuals and Community", the author, in Chapter 6, presents mathematicians in Lvov after World War I. We are informed that in 1920 the Lvov University changed its name to Jan Kazimierz University of Lvov (abbreviated UJK), and in 1924 the UJK Philosophy Department was split into the Department of Humanities and the Department of Mathematics and Natural Sciences. The latter department had four mathematics chairs, held by the following four professors: Eustachy Żyliński (from 1919), Hugo Steinhaus (from 1920), Stanisław Ruziewicz (from 1921) and Stefan Banach (from 1923). We also learn about Steinhaus's declaration (pages 29-30) of his greatest mathematical discovery, which in fact was, according to him, Banach.

Lvov Politechnic (PL) had three mathematics chairs, which were allocated to different departments and occupied by three professors: Antoni Łomnicki (since 1919), Włodzimierz Stożek (since 1922) and Kazimierz Kuratowski (since 1927). Kuratowski had a very productive time in Lvov (1927-1933), during which he published some forty papers, including joint papers with Banach and Ulam. Let us mention that there were few paying positions at UJK and PL, obtaining one was difficult, and the pay was low.

Chapter 7 concerns mathematical studies and students. We can read about the trimester teaching system, mathematical courses offered, exams, textbooks and the Lvov Student Circle. Chapter 8 is titled: journals, monographs and congresses. The new journal called Studia Mathematica started in 1929 (with the firstprint of 500 copies) and still continues (600 issues by now). The name was proposed by Antoni Łomnicki. During the years 19291940 a total of 161 papers were published in volumes 1-9, of which $70 \%$ were authored by Lvov mathematicians.

The next important event was the appearence in 1932 of Banach's monograph Théorie des opérations linéaires, which was the first volume of the series Mathematical Monographs 
(MM). It was an expanded edition of an earlier book that had appeared in Polish in 1931. The second monograph written by Lvov mathematicians was the Kaczmarz-Steinhaus book, Theorie der Orthogonalreihen, published in 1935 as volume 6 of Mathematical Monographs. In my opinion also volume 3 of MM published in 1933 by K. Kuratowski Topologie I. Espaces métrisables, espaces complets was written when Kuratowski was working in Lvov.

Lvov mathematicians participated actively in mathematical life. Every four years International Congresses of Mathematicians are held, and they are the most important and the most prestigious mathematical conferences in the world. It is a great honor to be invited to give a plenary lecture or sectional talk at the Congress. Lvov mathematicians participated in three congresses in Bologna (1928), Zurich (1932) and Oslo (1936). The author writes mostly about Banach's contribution to these meetings.

We should mention that in Bologna the Polish delegation was the seventh largest, consisting of 32 participants. From Lvov came: Banach, Chwistek, Kaczmarz, Antoni and Zbigniew Łomnicki, Nikliborc, Ruziewicz, Schauder, Steinhaus, Stożek and Żyliński. On September 8, 1928, Banach delivered a sectional talk, Sur les systèmes d'équations lineaires fonctionnelles. A twenty-strong group of Polish mathematicians participated in the next congress in Zurich. Sierpiński gave a plenary address Sur les ensembles de points qu'on sait définir effectivement and eleven Polish mathematicians delivered sectional talks. Among them two were from Lvov: Kuratowski and Ulam.

At the congress in Oslo, Banach gave a plenary address, Die Theorie der Operationen und ihre Bedeutung für die Analysis. He described the work of the whole Lvov school, and he also spoke of the plans of the Lvov mathematicians to develop their ideas further. Moreover, among the sixteen sectional talks there were four given by mathematicians from Lvov, namely Kaczmarz, Mazur, Orlicz and Schauder. S. Mazur and J. Schauder presented a talk Über ein Prinzip in der Variationsrechnung, in which they proposed an abstract approach to the existence of minimizers of variational problems.

Chapter 9, "The Popularization of Mathematics," lists academic and school textbooks written by mathematicians working at UJK and PL. Among authors were S. Banach, A. Łomnicki, W. Nikiliborc, W. Orlicz, S. Ruziewicz, W. Sierpiński, W. Stożek and E. Żyliński.

Chapter 10, entitled "Social Life", is devoted to the Scottish Café and the Scottish Book. Duda's description shows that the social life of the Lvov mathematicians was intimately connected with their mathematics, and makes clear that in the "Golden Age" it often mixed with humor, friendships and competitions. It starts with information about mathematical discussions, which took place in cafés near the university, first in "Roma" and after one year, in the "Scottish Café". We should mention that the atmosphere in Lvov was one of enthusiastic collaboration. People were very interested in each other's problems. This enthusiasm was an expression of satisfaction Poles that their country gained independence.

The table used by Banach, Mazur, and Ulam was the most important one in the Scottish Café. Mathematical conversations led to new theorems and exciting mathematics, but often were written only on the table tops. In 1935 Banach's wife, Łucja, bought a thick notebook to be kept in the Scottish Café for the mathematicians to use to record their problems, conjectures, comments and solutions. The notebook was available to any mathematician who asked for it at the café. It became known as The Scottish Book. The first problem was written by Stefan Banach on July 17, 1935 and the last one by Hugo Steinhaus on May 31, 1941. Some of the problems had prizes for their solution, like a cup of coffee, one small beer, five small beers, one bottle of wine, a bottle of wine of measure $>0$, lunch at the Dorothy, one kilo of bacon, and a live goose! The last one was offered by Mazur when he posed Problem 
153 in 1936 about an approximation property. In 1972 Per Enflo constructed a separable Banach space without the approximation property, thus a space without a Schauder basis. He presented a lecture on the solution in Warsaw, at which Mazur handed him a live goose as the award which he had promised in 1936. A Polish newspaper published a photo of the moment; it is a pity that the book under review does not contain a photo of such a remarkable event and that is why I attach the photo here.

The Scottish Book contains 198 problems, written mostly in Polish, but also in German, Russian, French and English. More than one hundred forty problems were formulated by the Lvov mathematicians, and the largest number of problems were written by Ulam ( $62=40$ of his own problems, plus 22 joint problems), Mazur $(47=22+25)$ and Banach $(23=14+9)$. Many renowned mathematicians who visited Lvov contributed to the book, e.g., P. Aleksandrov, M. Fréchet, John von Neumann, S. Sobolev and S. Eilenberg, who joined the community of mathematicians working and drinking in the Scottish Café and wrote six problems in the book. Today the original Scottish Book is in the custody of the Banach family; a copy is in the Library of the Mathematical Institute of the Polish Academy of Sciences in Warsaw. Duda presents a history of the book and information that in May 1979 at the North Texas University in Denton a Scottish Book Conference took place (Ulam, Kac, Erdös and Zygmund were among the participants). In 1981 a selection of problems from the Scottish book appeared as The Scottish Book, Mathematics from the Scottish Café (including selected papers presented at the above mentioned conference), which contains problems as well as some solutions and commentaries.

I myself have written comments to a positive solution of Problem 87 posed by Banach (pages 161-170). Moreover, jointly with A. Plichko and V. Mykhaylyuk we solved the problem of 188 posed by Eidelheit, and published the solution in [18]. The author ends this part citing three anecdotes. It is not mentioned that the last one is, in fact, about Juliusz Schauder.

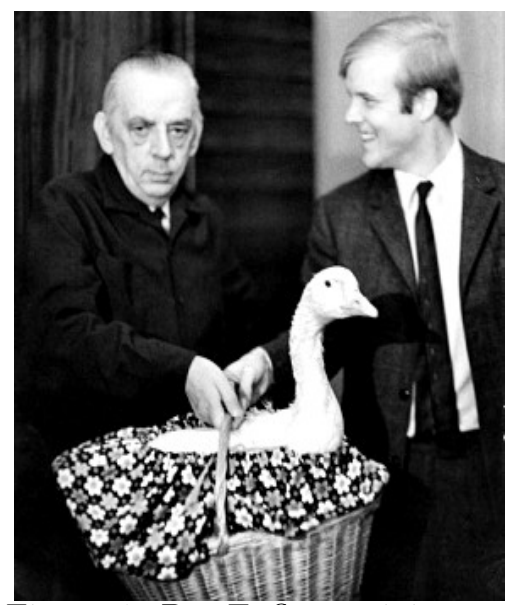

Figure 2. Per Enflo receiving a live goose from Stanisław Mazur in 1972 for solving problem 153 in The Scottish Book

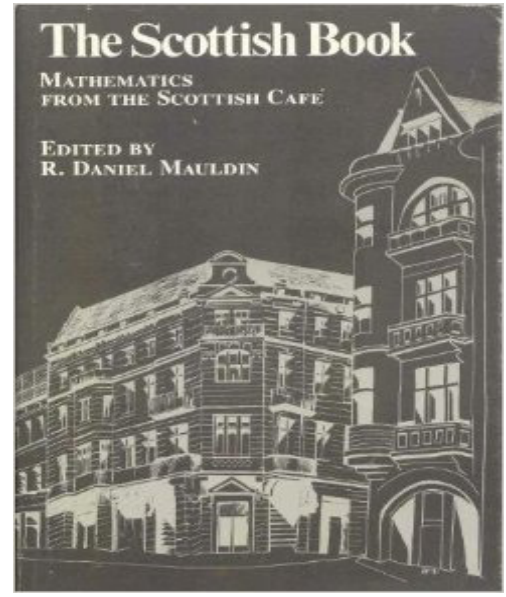

Figure 3. Cover of The Scottish Book from 1981

In Chapter 11, we can read about the formation of the Polish Mathematical Society (PTM) in 1920. There is also information about official meetings of the Lvov PTM branch, which took place Saturday evenings, almost every week! In years 1928-1938 a total of 180 meetings were held, during which 360 talks were given. The most active speakers were: Stefan Banach (43 talks), Hugo Steinhaus (35), Juliusz Schauder (24), Stanisław Ulam (24), Władysław Nikliborc (22) and Władysław Orlicz (21 talks).

In Chapter 12, entitled "Collaboration with Other Centers", the reader is informed about visitors to Lvov, among whom there were known figures such as Ernest Zermelo (1871-1953), John von Neumann (1903-1957), Henri Lebesgue (1875-1941), Emil Borel (1871-1956), Paul Montel (1876-1975), Jean Leray (1906-1998), Leon Lichtenstein (1878-1933) and Witold Hurewicz (1904-1956). Moreover, multiple short or long visits were made by Zygmund and Marcinkiewicz from Vilnius and by Sierpiński, Mazurkiewicz, Knaster, Tarski and Borsuk 
from Warsaw.

Chapter 13 reveals the kaleidoscope of mathematical types in Lvov. Every mathematician is an individual with specific gifts and his own interests and viewpoints. The mathematicians: Stefan Banach, Hugo Steinhaus, Stanisław Mazur, Kazimierz Kuratowski, Stanisław Ulam, Juliusz Schauder (whose photos are included) and Zbigniew Łomnicki, Włodzimierz Stożek, Herman Auerbach (without photos) are described as seen "in the eyes of others." In the last subchapter 13.9, there are brief mentions of such persons as Kac, Kaczmarz, Orlicz, Ruziewicz, Schreier, Żyliński. It seems to me that a little more should be written about them.

In Part III, we find information about the most important achievements of the Lvov School of Mathematics in functional analysis, probability theory, measure theory, partial differential equations, game theory, algebras and combinatorics.

Chapter 14 begins with a discussion of results from Banach's doctoral thesis, completed in 1920 and published in 1922. As we can read in the footnote 57: Banach cared much more about getting results than getting things published, and this might explain delay in publication. Banach gave the first axiomatic definition of a space, later named in his honor a Banach space. He himself did not put any name on this space. The term a space of type $(B)$ was introduced by Steinhaus (Studia Math. 1 (1929), p. 54). Then Banach was using this name in his books (Polish version from 1931 and French version from 1932) and in two papers with S. Mazur only in 1933 (Studia Math. 4 (1933), p. 90 and p. 100). The term Banach space was introduced by Maurice Fréchet in 1928 in his book on metric spaces and the name is attributed to Steinhaus who, quoting Fréchet, was the first person to call a type $(B)$ space a Banach space in 1929. For a short time it went by the name Banach-Wiener space, but in 1923 Norbert Wiener himself acknowledged the priority of Banach (cf. pages 89-90).

On page 89 Banach's fixed point theorem (or Banach's theorem on contraction) in Banach spaces is presented, which is an abstract version of the method of successive approximations. Let us mention here that the Italian mathematician Renato Caccioppoli observed in 1930 that Banach's proof works for complete metric spaces. Therefore, this result is also known as the Banach-Caccioppoli fixed point theorem (at least in Italy and Russia).

Chapters 15-18 present the main achievements of the Lvov School from the 1920s. The presentation begins with first papers by - Eomnicki and Steinhaus - where probability was considered as a measure. Both papers were published in Fundamenta Mathematicae in 1923. Łomnicki's paper was submitted in 1920, however, Steinhaus's paper in 1922. They do not cite each other! Axiomatization of probability, using measure theory, was finally done by Kolmogorov in 1933. Steinhaus does not cite the Kolmogorov in his work and he didn't accept his axioms. Rather, he defined the stochastically independent functions (similarly to independent random variables), and in the years 1936-1940 he published, together with M. Kac, six papers concerning such functions. The English translation of this Chapter 15 has only the first part "Probability Theory" of the original Polish version; it omits the second part, "Semi-Final in the Mathematization". This title is connected to Urbanik's quote from 1973: In the language of the sports commentator, one can say Kolmogorov got to the final, but the two Polish mathematicians A. Eomnicki and H. Steinhaus got to the semifinals.

Next, Duda initiates discussion about the measure problem, which has no solution in $\mathbb{R}^{n}$, for $n>2$, as was proved by Hausdorff in 1914. Then in 1923 Banach showed - contrary to expectations - that for $n=1$ and $n=2$ the answer is positive. Banach's solution caused quite a stir, although he used in the proof the axiom of choice. Moreover, Duda presents the history of the Banach-Tarski paradox from 1924 and information that Banach was interested 
in measure-theoretic questions for the rest of his life.

In Chapter 17, entitled "Game Theory: a Revelation Without Follow-up", we find information about a short work of Steinhaus from 1925, which was published in a minor one-day academic brochure and it was revelatory because game theory was still in its infancy (revelation occured after its translation into English in 1960). The author, however, does not mention Mazur's problem from 1928 (problem 43 in the Scottish Book), which was solved by Banach in 1935, but the proof was never published. It is known now as the Banach-Mazur game (see [21], pp. 113-117).

In "Operator Theory in the 1920s" (Chapter 18) there is history and formulation of the Hahn-Banach theorem on extension of functionals in the real and the complex case, which is one of the fundamental theorems in functional analysis (completeness is not needed for the formulation). The original Hahn-Banach theorem was proved only in the real case, by Hahn in 1927 and by Banach in 1929. Hahn was working with the norm on a bigger real vector space, but Banach worked only with a sublinear (more precisely, subadditive and positively homogeneous) functional. The complex case was proved only in 1938 by Bohnenblust-Sobczyk and Soukhomlinov. We can read more on the history of the HahnBanach extension theorem in Pietsch's book [27, pp. 39-40] and in a survey paper by Narici and Beckenstein [23].

In the same chapter we also have information that Banach's paper introduced dual space $X^{*}$ to a Banach space $X$ and a dual operator. Then, the solution of Fréchet-Banach's (not Mazur's) problem that every infinite-dimensional Fréchet space is homeomorphic to a Hilbert space is discussed, which the author identifies as the Kadets-Anderson theorem (1966, page 107). Hovewer, they assume separability and the general case is due to Toruńczyk (1981). The author continues with Schauder's domain-invariance theorem (1930), Schauder's fixed point theorem (1927), Mazur's applications of functional analysis in summability theory (1930), Mazur's basis problem, the Banach-Mazur theorem on universality of $C[0,1]$ and the Banach-Ulam isometry theorem (1932).

In Chapter 19 we can find information about the audacity of the Lvov school in using nonconstructive methods which establish the existence of a mathematical object without specifically constructing it directly, such as proving the existence of continuous, nowhere differentiable functions without actually constructing one (Banach 1931, Mazurkiewicz 1931). The source of these constructions were the axiom of choice, Baire's category theorem from 1899 and the Lebesgue measure with the Lebesgue integral.

In Chapter 20, it is finally time to discuss Banach's monograph as "Polishing the Pearls" (the original Polish title was "Framing the Pearl"): S. Banach, Théorie des opérations linéaires, Monografie Matematyczne, Tom 1, Warszawa 1932, viii +252 pages (in French). Banach's book is dedicated to his wife Lucja ( $\grave{A}$ Madame Lucie Banach) and consists of a foreword, introduction, twelve chapters, an appendix, notes and an index of names. An important part of the monograph

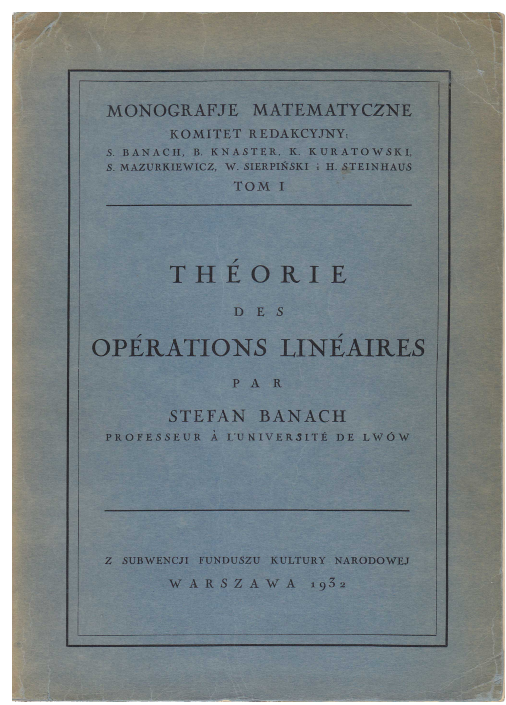

Figure 4. Cover of Banach's book from 1932 are the Remarks (Remarques), which were written by S. Mazur. They include historical comments, remarks about the links between different notions and theorems, open questions and pointers for further research. The Ukrainian translation 
of Banach's book updated the "Remarks" section (cf. [24]).

This work is Banach most influential, with fundamental theorems in functional analysis, including the Hahn-Banach extension theorem (real case), the Banach-Steinhaus theorem on uniform boundedness, the open mapping theorem and the Banach fixed point theorem. His notation and terminology were widely adopted. J. D. Tamarkin wrote in his review of Banach's book (cf. [33], p. 13): It represents a noteworthy climax of long series of researches started by Volterra, Fredholm, Hilbert, Hadamard, Fréchet, F. Riesz, and successfully continued by Steinhaus, Banach, and their pupils. (...) The theory of linear operations is a fascinating field in itself but its importance is still more emphasized by numerous beautiful applications to various problems of analysis and function theory. A number of these applications are contained in the book.

Duda discusses in detail the contents of the book, and its importance in the world is evoked by quoting Bourbaki, Birkhoff-Kreyszig, Szökelfalvi-Nagy and Stone. I can complete this discussion by listing all translations and editions of Banach's book: a Ukrainian translation by M. Zaryckij entitled A course of functional analysis, Kyiv 1948, 216 pp. (the translation was planned and prepared in 1939-1940, but appeared only in 1948 - cf. [28]); reprints in French, Chelsea, New York 1955, 1988; reprint in the book: Stefan Banach, Ouvres. Vol. II. Travaux sur l'analyse fonctionnelle, PWN, Warsaw 1979, 13-219; an English translation from French by F. Jellett, North-Holland, Amsterdam 1987, x+237 pp.; Éditions Jacques Gabay, Sceaux 1993 and a Russian translation by L. I. Tuchinskij, Izhewsk 2001, 272 pp. Let us mention that the French version of the book appeared a year after the Polish version from 1931: Stefan Banach, Teorja operacyj. Tom I. Operacje linjowe, Warszawa 1931, viii+236 pp.

In Chapter 21, entitled "Operator Theory in the 1930s: the Dazzle of Pearls" the main achievements of the Lvov School in operator theory are described, namely: spaces (Banach spaces, Orlicz spaces, Schauder spaces, Schreier spaces, $B_{0^{-}}$ spaces and $L^{\infty}$-space as a dual to $L^{1}$ ), three fundamental theorems (Hahn-Banach theorem on extending functionals, Banach-Steinhaus theorem on uniform boundedness and open mapping theorem) and other results: Banach-Steinhaus theorem on condensation of singularities, origins of duality theory, introduction of topological methods in Banach spaces (convexity, hyperplanes, unconditional convergence), approximation property and the inverse mapping theorem.

The theory of Banach spaces initiated and substantially developed in Lvov is now referred to as classical Banach space theory. The next golden age was the period 1950-1980, when Polish mathematicians would also make significant contributions (A. Pełczyński [25] even gave plenary address at the Warsaw ICM in 1983), about what we read in the books by

$\mathrm{D}^{\mathrm{n}}$ STEFAN BANACH

TEORJA OPERACYJ

OPERACJE LINJOWE Lindenstrauss and Tzafriri (1977, 1979), Rolewicz [31], Albiac and Kalton (2006), and Pietsch [27].

Then, in Chapter 22, "New Perspectives for which time did not allow", the author mentions the following topics, for which the Lvov School did not have enough time or energy: nonlinear functional analysis (with Juliusz Schauder's results like the fixed point theorem in Banach spaces, the open invariance theorem, Leray-Schauder topological degree, Banach and 
Mazur-Orlicz polynomial operators between Banach spaces); the theory of partial differential equations (Schauder's results from 1932-1937, including Schauder a priori estimates concerning the regularity of solutions: 1934, 1937); the theory of linear topological spaces (Mazur's locally convex spaces from 1935, $B_{0}$-spaces of Mazur and Orlicz); the theory of recursive functions (in 1937 Banach and Mazur developed idea of Turing from 1936, but the monograph of Mazur on this subject appeared only in 1963); algebra, specifically Banach algebras (Mazur-Gelfand theorem, Eidelheit's results and Mazur-Turowicz's unpublished paper from 1939, in which they had a proof of the Stone theorem on approximation); noncommutative probability theory (Steinhaus' paper from 1938 on the subject of independence leading to a noncommutative theory of probability); graph theory (Kuratowski's theorem from 1930 on planar graphs, which is now one of the most basic theorems in modern graph theory; this part was not in the Polish version of the book); applications of mathematics and numerical analysis.

Steinhaus's achievements are described, and let us quote a part of Steinhaus's credo regarding the application of mathematics: People go to doctors to seek advice, but not to mathematicians. Would they go to see a doctor if they could only attend medical lectures and if there were no hospitals, clinics, or pharmacies, if the only people available were professors or teachers of hygiene, but nobody who could actually examine them and prescribe them medicine?

It is mentioned that in numerical analysis one of the most frequently cited works is the work of Kaczmarz from 1937 where he described a method that provides approximate solutions to systems of linear equations with many variables. It is now known as Kaczmarz's method or Kaczmarz's algorithm. There is no doubt that Kaczmarz's method, together with Banachiewicz's Cracovian calculus and decoding of Enigma are the greatest achievements in computational mathematics made by the Polish mathematical school in the interwar period.

The Polish version of Banach's book from 1931 concerns linear operators, as mentioned in the title. In 1935 a notice appeared on the back cover of Mathematical Monographs, Vol. 6, about an upcoming book by Banach Théorie générale des opérations and it was also repeated on back covers in Volumes 7 (1937), 8 (1938) and 10 (1938).

Unfortunately, we don't know what he was planning to write about. Maybe on fixed point theorems and polynomial operators? However, I would like to mention that problem 87 in the Scottish Book concerns a nonlinear version of the Riesz-Thorin interpolation theorem. My comments to this problem can be found in [21] on pages 161-170.

We can also note that were plans to print the following three books in Mathematical Monographs (cf. Fig. 6): S. Mazur, Allgemeine Limiterungstheorie [General Theory of Summability], J. Schauder, Partielle Differentialgleichungen vom elliptischen Typus [Partial Differential Equations of Elliptic Type] and A. Tarski, Arithmetik der Kardinalzhalen [Arithmetic of Cardinal Numbers].

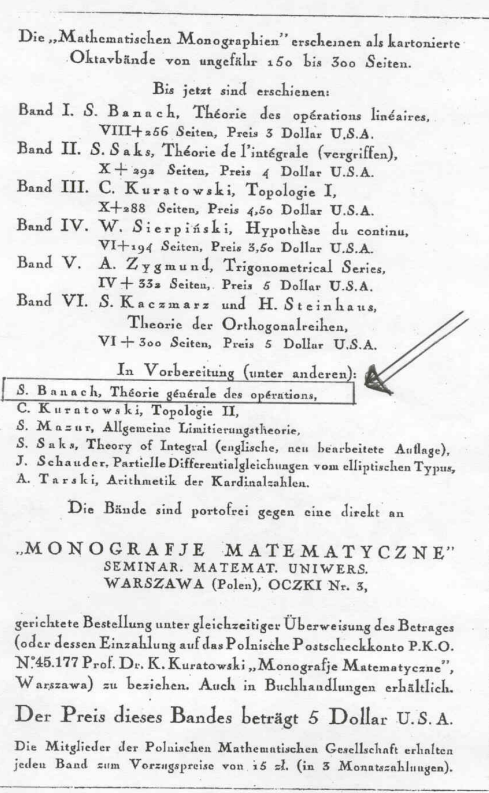

Figure 6. Announcement about second volume of Banach's book

In Chapter 23, "On the Periphery," there is information on more peripherical subjects of the Lvov School, among which there were: logic (we find Żyliński's result from 1925, explanation why the chair of mathematical logic at UJK in 1930 
was given to L. Chwistek instead of A. Tarski and a description of research directions of Pepis, Hetper and Hercberg), classical analysis (research of W. Nikliborc in approximation methods for the solutions of differential equations, pluriharmonic functions and the threebody problem), mathematical cartography (activity of A. Łomnicki is mentioned, including information about his textbook from 1927 and 1956), geometry (Auerbach's conjectures on convex geometry, solved in 2011 by Fusco and Pratelli), perspective in painting (K. Bartel's area) and actuarial mathematics (Z. W. Birnbaum, M. M. Jacob, Z. Łomnicki and L. Sternbach).

Part IV called "Oblivion" is devoted to the destruction of the Lvov School and three Chapters 24-26 discuss respectively "Ukrainization the Soviet Way (1939-1941)", "The German Occupation (1941-1944)" and "The Expulsion of Poles (1945-1946)".

The time when it was possible to concentrate on mathematics ended on the September 1, 1939. On September 22, 1939, Germans gave Lvov to Russians on the basis of the MolotovRibbentrop Pact, a non-aggression pact signed between Nazi Germany and the Soviet Union in Moscow in the late hours of August 23, 1939. The Soviets closed down both UJK and the Polytechnic, and in November the same year replaced them with the Ukrainian University, renaming them on January 8, 1940, as the Ivan Franko University and the Lvov Polytechnical Institute (in the book it is written Ukrainian Polytechnical Institute but it should be Lvov Polytechnical Institute).

Mathematics did not suffer much. Banach remained the dean of the Department of Physics and Mathematics (the only Polish dean at the Ukrainian University) and M. Zaryckij was made the vice dean. The staff list for six chairs of mathematics includes S. Banach (Analysis I), H. Steinhaus (Analysis II), S. Mazur (Geometry), E. Żyliński (Algebra), M. Zaryckij (Probability Theory) and J. Schauder (Mechanics). University lectures were delivered in the Polish language and even Volume 9 of Studia Mathematica appeared, dated 1940. In the period of January 29-February 3, 1941, a conference was held at the Ivan Franko University, about which we can read on the pages 137-138. Academic visits of Soviet scientists in Lvov were relatively frequent and several mathematicians from Lvov visited Moscow (Żyliński in 1940, Banach, Mazur and Schauder in 1941), Kyiv (Banach, Mazur, Zaryckij in December 1940 and Banach also in 1941), and Tbilisi (Banach and Zaryckij in 1941).

Life was very far from normal, and Soviet propaganda with socialist ideology was the political priority. There were constant and endless meetings and reorganisations. There was constant threat of arrest without warning, imprisonment and deportation.

The German occupation of Lvov started one week after the start of the Russo-German war and lasted three years (June 30, 1941-July 27, 1944). In July 1941 several professors were arrested and executed, including mathematicians K. Bartel, A. Łomnicki, S. Ruziewicz, W. Stożek and K. Vetulani. The Lvov institutions of higher education, including the university and the politechnic, were closed down by the Germans. Only elementary schools continued, and in spring 1942 a two-year State Commercial School in Polish language was established. A few Lvov mathematicians found employment there. Several professors had to feed the lice in Professor Weigl's Bacteriological Institute, including Banach, Knaster and Orlicz*.

Rudolf Stefan Weigl (1883-1957) was a Polish biologist and inventor of the first effective vaccine against epidemic typhus. He was born on September 2, 1883, in Prerov, Moravia, as an Austrian with Germanspeaking parents. When he was a child, his father died in a bicycle accident and his mother married a Polish secondary-school teacher, Józef Trojnar. Later the family moved to Lvov and Weigl was educated in Polish culture. He founded the Weigl Institute in Lvov, where he conducted vaccine research. The typhus vaccine was produced on a large scale in Weigl's laboratory before World War II in Lvov, and used in China 
The following Lvov mathematicians did not survive the German occupation (1941-1944): H. Auerbach, K. Bartel, M. Eidelheit, J. Hercberg, M. Jacob, A. Łomnicki, S. Ruziewicz, J. Schauder, J. Schreier, L. Sternbach, W. Stożek, K. Vetulani and M. Wojdysławski.

On July 27, 1944, the Soviet Army with the help of Polish Home Army liberated Lvov. The academic institutions started functioning again-the university opened in September and Polytechnic in October 1944. The heads of the Department of Mathematics and Mechanics at the Ukrainian University of Lvov for the academic year 1944/45 were the following: S. Banach (Mathematical Analysis), W. Orlicz (Theory of Functions), S. Mazur (Geometry), E. Żyliński (Algebra), W. Nikliborc (Theoretical Mechanics) and M. Zaryckij (General Mathematics).

In October 1944, S. Mazur was summoned to Moscow, where he was informed about the new Polish borders and about the plan to resettle Poles. After the war Lvov was annexed by the Soviet empire. From April 1945, to May 1946, almost all surviving Poles in the area, including the living rest of mathematicians, were expelled from their home city because Allied Powers (international alliance of Great Britain, the Soviet Union and the United States) decided that the eastern part of Poland (invaded by Stalin in 1939) was to become a part of the Soviet Union. Banach died in Lvov on August 31, 1945, and he was buried at the Łyczakowski Cementery in Lvov in the Riedel family tomb. In that way the Lvov School of Mathematics was eventually eradicated and ceased to exist.

In Part V, "Historical Significance", there is, starting in Chapter 27, a "Chronological Overview" (on nine pages, 155-163) of the key information about Lvov mathematicians, including doctorates, habilitations, professorships as well as some publications and results given in their chronological order in the years 1919-1945.

In Chapter 28, "Chronology of Events as Perceived Elsewhere" the author uses a list of the most important mathematical works of different mathematicians during the years 19001950, done by P. Dugac, B. Eckmann and J. Mawhin. More precisely, in 1994 J.-P. Pier edited a book Development of Mathematics 1900-1950, where such a list appeared (on pages 1-34) and Duda in this part lists the names of Polish mathematicians appearing on that list with bold font for the names of Lvov mathematicians. In this collection Banach's name appeared 6 times, the name of Steinhaus 4 times, Schauder's name 5 times and Mazur's name 3 times.

Chapter 29, "Influence on Mathematics of the Lvov School", begins with personalities. The founders and leaders were Hugo Steinhaus and Stefan Banach. For active members of the school their doctorates and/or habilitation degrees, awarded at Lvov during the years 19241938, are listed. Chronologically, the following doctorates were awarded: 1924 Kaczmarz, Nikliborc, Schauder, 1927 Weinlös, 1928 Orlicz, 1929 Birnbaum, 1930 Auerbach, Zaryckij, 1932 Mazur, Schreier, 1933 Ulam, 1937 Kac, Hetper, 1938 Eidelheit and Pepis.

Then, we find a comment that many important results obtained at Lvov were either published too late or not at all, supported with several examples. There is also a collection

(Rutten 1936, 1943), Ethiopia (Mariani 1939) and other countries. When Germans occupied Lvov (19411944), they ordered Weigl to set up a vaccine production plant at his Institute. Over five hundred people worked there (a list can be found at http://www.lwow.home.pl/weigl/weiglowcy.html). Weigl employed and protected Polish intellectuals, Jews and members of the Polish undeground. His vaccines were smuggled into ghettos in Lvov and Warsaw, saving countless lives, until the Institute was shut down by the Soviet Union following their 1944 anti-German offensive. In 1945 Weigl moved to Kraków (Cracow) as Professor of General Microbiology at the Jagiellonian University (1945-1948), and finally to the University of Poznań (1948-1951). Production of the vaccine remained at Kraków for some years. After retirement, Weigl died on August 11, 1957, in the Polish mountain resort of Zakopane, reaching 74 years of age. More information can be found in [32] and in [1]. 
of weak points of the Lvov school taken from the Pełczyński-Semadeni article from 1969. I would like to mention two of them: the Lvov mathematicians were considering real Banach spaces neglecting spaces defined over the complex numbers, and by concentrating on bounded linear operators, also neglected unbounded operators. Despite these weaknesses, the Lvov School of Mathematics was nonetheless an institution of the highest class and its legacy occupies a permanent place in the history of mathematics. The names "Banach" and "Banach spaces" will remain permanently in mathematics.

Let us quote from Chapter 30, "A Tentative Summary": The strongest field of the Lvov School of Mathematics was the theory of Banach spaces and, even more generally, functional analysis. (...) At the congress in Oslo, there was Banach's promotion and there was news of Lvov's interesting mathematcal culture (the PTM meetings, the caffe life, the Scottish Book) - all of this made the Lvov center particularly attractive and gave it world status. (...) Only a few active members of the Lvov mathematical school lived to see the end of the war.

In Chapter 31, "Mathematics in Lvov After 1945," we find information that Zaryckij was appointed dean of the Department of Mathematics and Physics. The departamental chairs were filled by people from the heart of the Soviet Union. Among newcomers were B. V. Gnedenko, A. S. Kowańko, Ju. Ja. Łopatyńskij and L. I. Wołkovyskij.

In Part VI, entitled "List of Lvov mathematicians," there is a list of 55 "Mathematicians Associated with Lvov" together with their short CVs, in alphabetical order. Among those listed the most active members in the period 1918-1945 were the following mathematicians or logicians: Stefan Banach (1892-1945), Zygmunt Wilhelm Birnbaum (1903-2000), Lucjan Emil Böttcher (1872-1937), Leon Chwistek (1884-1944), Meier Eidelheit (1910-1943), Jan Hercberg (1908-1941?), Władysław Hetper (1909-1940?), Marian Mojżesz Jacob (19001941), Mark Kac (1914-1984), Stefan Kaczmarz (1895-1940), Kazimierz Kuratowski (18961980), Antoni Marian Łomnicki (1881-1941), Stanisław Mazur (1905-1981), Władysław Nikliborc (1899-1948), Władysław Orlicz (1903-1990), Józef Pepis (1910-1943?), Stanisław Ruziewicz (1889-1941), Juliusz Paweł Schauder (1899-1943), Józef Schreier (1909-1943), Wacław Sierpiński (1882-1969), Hugo Steinhaus (1887-1972), Ludwik Sternbach (19051942), Włodzimierz Stożek (1883-1941), Stanisław Marcin Ulam (1909-1984) and Eustachy Żyliński (1889-1954). Some new information about some of these mathematicians can be found in the recently published papers [12]-[15] and [20].

Finally, in Part VII, there are collected "Bibliographies" and we have in Part A. Mathematical works by Lvov mathematicians (pp. 195-204), in Part B. Personal recollections, surveys, and historical source material (pp. 205-217) and in Part C. Other mathematical works cited (pp. 219-223). The book ends with the "List of illustrations and acknowledgments" (pp. 225-226) and the "Index of names" (pp. 227-231). There is no subject index.

Like every book, this one is also not free of misprints or errors. The Mathematical Intelligencer asked me to put the list of typos and errors in MR (MathSciNet), who just informed me to sendthem only to the author, so I am collecting them here.

The photo on page 42 is from 1931 not from 1930, on page 85 it is written that Banach and Steinhaus showed that a certain integrable function cannot exist but, in fact, they constructed a counterexample, that is, such a function exists; contrary to what we read on page 88 translations are not linear operators except identity; Łomnicki was not the advisor of Banach (p. 85); on page 92 in line 12 from above we have "all possible distances," but it should be "all possible differences"; on pages 108, 121, 228 the name Enflo has erroneously two dots over "o" (by the way, many Polish authors have also misspelt Enflo's name). 
On p. 108 we read that Banach and Mazur proved that every normed separable space is isometrically isomorphic to some subspace of $C[0,1]$ and it was the first example of a universal space for some class of locally compact spaces - it should be "locally convex" instead of "locally compact." On the same page, the Mazur-Ulam isometry theorem is not formulated as it was in their original paper. They proved that every surjective isometry $f: U \rightarrow V$ between two real normed spaces is affine, that is, $\|f(x)-f(y)\|=\|x-y\|$ for all $x, y \in U$ implies that the map $T: U \rightarrow V$, defined by $T(x)=f(x)-f(0)$, is linear. Then, in 1971, Baker proved their result without the assumption "onto," but he needs a strict convexity assumption on the space $V$ (namely, if $x, y \in V, x \neq 0, y \neq 0$ and $\|x+y\|=\|x\|+\|y\|$, then $x=\lambda y$ for some $\lambda>0$ ). Lindenstrauss-Tzafriri volumes (p. 119) were not updated. On p. 119 it is written that the idea for Orlicz spaces $L^{\Phi}$ had already appeared in Birnbaum-Orlicz paper from 1931. This statement is not true since they where proving Landau's theorem and did not introduce any spaces at all. Orlicz spaces as Banach spaces appeared only in an Orlicz paper from 1932 (with the so-called $\Delta_{2}$-condition on $\Phi$ ) and the Orlicz paper from 1936 without this additional condition on $\Phi$. On p. 120 we have space metrizable in a convex sense, but I think it should be locally convex metrizable space. On p. 136 is A. Plamitzer but it should be H. Plamitzer (Helena not Antoni). On p. 141, the reference to Eomnicki is [B: Maligranda, 2007] but it should be [B: Maligranda, 2008]. On p. 186 we are reading that "Orlicz produced 171 papers in functional analysis," but more accurate would be: "Orlicz produced 171 papers in functional analysis, theory of functions, integration theory and theory of orthogonal series" (see [B: Maligranda and Wnuk 2000]). On p. 182 it is "Kaczmarz, Stefan (1895-1940)," but the year 1940 should be replaced by 1939 (see [B: Maligranda 2007]). On p. 186 is Pepis, Józef (1910-1943?), but the year 1943 should be replaced by 1941 (cf. [20], p. 38). On p. 191 is "Żyliński authored several papers and a couple of textbooks," but it would be more precise to write: "Żyliński authored over 20 papers in number theory, algebra, logic, foundations of mathematics and 6 textbooks" (cf. [12]). On p. 198: the Kaczmarz-Steinhaus book was not translated into English. The 1951 edition is a reprint in the German language.

Some misprints (page ${ }^{\text {line }}$ or page line $\left._{\text {e }}\right): 8^{23}$ Opiał $\rightarrow$ Opial; $49^{13} 1 \mathrm{Ow} \rightarrow$ low; $58_{5}$ Soboloev $\rightarrow$ Sobolev; $68^{3}$ (one name under the figure 15) Marcinkiewicz $\rightarrow$ Mazurkiewicz; $106^{10}$ functionals $\rightarrow$ operators; $106^{14} y=U(x) \rightarrow y=U^{*}(x) ; 106^{17}$ atypical $\rightarrow$ a typical; $106_{15}$ superfluous parentheses "]"; $107_{3-4}$ the convex closure of a compact $\rightarrow$ the closure of a convex compact; $180^{5}$ Riedle $\rightarrow$ Riede; $147_{2}$ Rapaport $\rightarrow$ Rappaport; $160_{3}$ Jözef $\rightarrow$ Józef.

Many journal articles have been devoted to various aspects of mathematics in Lvov or to biographies of Lvov mathematicians, but Duda's book is the first comprehensive exposition. The first original Polish edition of the book from 2007 (Lwowska Szkota Matematyczna, Wydawnictwo Uniwersytetu Wrocławskiego, Wrocław 2007 - cf. [5]) generated much interest in Poland, evidenced by eight favorable reviews in both specialist and general journals, and the fact it won the prize for Poland's best academic book of the year 2008. I believe that the English version will also be successful.

Since the publication of the first edition new documents have come to light and some new works have appeared, which has made it possible to implement minor corrections, and provide extra substance to the main text in several places, while including some new entries in the bibliography. For further reading about mathematicians and mathematics in Lvov I recommend the following literature (unfortunately, some only in the Polish language): the books [7]-[9], [27], [30], and the following useful or new articles (not cited in Duda's book): [2], [4], [10]-[15], [19]-[20], [23]-[26], and [28]-[29]. Moreover, let me mention that the second edition of Duda's Polish version of the book appeared in 2014 (cf. [8]). 
The second edition has ten pages more than the first one, i.e., 266 pages, where has been added a little history, two photos: Ulam on page 92 and photo 28 on page 166 with the unveiling on July 3, 2011, of the monument Polish Lvov university professors were shot by the Germans in July 1941, in the 70th anniversary of the murder and forty entries of additional literature, including 6 papers by Duda, 14 papers by Przeniosło (however, not the book [30]), 4 papers by Prytuła and papers [13], [20]. In the second edition there were also corrected the Banach theorem on fixed point (p. 104), the Schauder theorem on inverse of operators (p. 124) and the Mazur theorem on relative compactness of the convex hull (p. 125). Colorful pictures and scans in the first edition look much better than the black-and-white ones in the second edition.

In 2015 Roman Duda received the Mayor of Wrocław Award for two Polish editions and English translation of the book about the Lvov School of Mathematics. The same award for 2015 was also received by the translator of Duda's book - Daniel Richard Marian Davis born in Nowa Huta near Kraków (Poland) and educated in England.

Finally, I can conclude that Duda's book is a must-read for everyone interested in the history of functional analysis or of mathematics in Poland.

Acknowledgements. I thank Margaret Stawiska-Friedland (Mathematical Reviews) and Emelie Kenney (Loudonville, NY) for helpful suggestions. Also, it should be noted that a revision of the text by Mauldin [21] is currently published [22].

\section{REFERENCES}

1. A. Allen, The fantastic laboratory of Dr. Weigl. How two brave scientists battled typhus and sabotaged the Nazis, Norton, New York, 2014.

2. K. Ciesielski, On Stefan Banach and some of his results, Banach J. Math. Anal., 1 (2007), №1, 1-10.

3. K. Ciesielski, Z. Pogoda, On mathematics in Kraków through the centuries, Eur. Math. Soc. Newsl., 86 (2012), 19-24.

4. K. Ciesielski, M. S. Moslehian, Some remarks on the history of functional analysis, Ann. Funct. Anal., 1 (2010), №1, 1-12.

5. R. Duda, The Lvov School of Mathematics, University of Wrocław Publisher, Wrocław, 2017. (in Polish)

6. R. Duda, The Lvov School of Mathematics, Eur. Math. Soc. Newsl., 78 (2010), 40-50.

7. R. Duda, Mathematicians of XIX and XX century associated with Poland, University of Wrocław Publisher, Wrocław, 2012. (in Polish)

8. R. Duda, The Lvov School of Mathematics, 2nd Edition, University of Wrocław Publisher, Wrocław, 2014. (in Polish)

9. E. Jakimowicz, A. Miranowicz (eds.), Stefan Banach: Remarkable Life, Brilliant Mathematics, Biographical materials. 3rd ed., Gdańsk Univ. Press, Gdańsk, 2011, and Amer. Math. Society, Providence, 2011.

10. G. Köthe, Stanislaw Mazur’s contributions to functional analysis, Math. Ann., 277 (1987), №3, 489-528. MR0891589 (88i:01112)

11. L. Maligranda, Stefan Banach, in: "The Princeton Companion to Mathematics", editors T. Gowers, J. Barrow-Green, I. Leader, Princeton University Press, Princeton, 2008, 809-811.

12. L. Maligranda, Eustachy Żylinski (1889-1954), Antiq. Math., 3 (2009), 171-211. (in Polish)

13. L. Maligranda, Józef Schreier (1908-1943). Biography, Wiad. Mat., 49 (2013), №2, 47-60. (in Polish)

14. L. Maligranda, The scientific activity of Józef Schreier, Wiad. Mat., 50 (2014), №1, 45-68. (in Polish)

15. L. Maligranda, Meir (Maks) Eidelheit (1910-1943), Wiad. Mat., 51 (2015), №1, 31-59. (in Polish)

16. L. Maligranda, Review of the book "R. Duda, Pearls from a lost city. The Lvov school of mathematics, History of Mathematics 40 AMS, Providence, RI, 2014", MR32227799, 5 p. 
17. L. Maligranda, Review of the book "R. Duda, Pearls from a lost city. The Lvov school of mathematics, History of Mathematics 40 AMS, Providence, RI, 2014”, Mathematical Intelligencer, 39 (2017), №1, 74-76.

18. L. Maligranda, V.V. Mykhaylyuk, A. Plichko, On a problem of Eidelheit from The Scottish Book concerning absolutely continuous functions, J. Math. Anal. Appl., 375 (2011), №2, 401-411.

19. L. Maligranda, J.G. Prytuła, The hearings of Stefan Banach from 1944, Wiad. Mat., 48 (2012), №1, 51-72. (in Polish)

20. L. Maligranda, J.G. Prytuła, Lvovian scientists mentioned in Banach's hearings from 1944, Wiad. Mat., 49 (2013), №1, 29-66. (in Polish)

21. R.D. Mauldin, The Scottish Book: Mathematics from the Scottish Café, Birkhäuser, Boston, 1981.

22. R.D. Mauldin, The Scottish Book. Mathematics from the Scottish Café, with Selected Problems from the New Scottish Book, 2nd updated and enlarged edition, Birkhäuser, 2015.

23. L. Narici, E. Beckenstein, The Hahn-Banach theorem: the life and times, Topology Appl., 77 (1997), №2, 193-211.

24. M.I. Ostrovskii, A.M. Plichko, On the Ukrainian translation of Théorie des opérations linéaires and Mazur's updates of the "remarks" section, Mat. Stud., 32 (2009), №1, 96-111.

25. A. Pełczynski, Structural theory of Banach spaces and its interplay with analysis and probability, in: Proceedings of the International Congress of Mathematicians, V.1, 2 (Warsaw, 1983), PWN, Warsaw 1984, 237-269.

26. A. Pełczynski, Cz. Bessaga, Some aspects of the present theory of Banach spaces, in "Stefan Banach, Oeuvres", V.2, PWN, Warszawa, 1979, 223-304.

27. A. Pietsch, History of Banach spaces and linear operators, Birkhäuser, Boston, 2007.

28. A.M. Plichko, Ya.G. Prytula, The 60th anniversary of the publication of the Ukrainian translation of S. Banach's book, Mat. Stud., 30 (2008), №1, 107-112. (in Ukrainian)

29. J. Prytuła, Doctorates in mathematics and logic from the Jan Kazimierz University in Lwów during the years 1920-1938, in: "History of Polish Mathematics", Inst. Mat. Uniw. Wroc., Wrocław, 2012, 137-161; Reprint Antiq. Math., 4 (2010), 137-161.

30. M. Przeniosło, Polish Mathematicians in the Interwar Period. A Historical Study, University of Humanities and Sciences of Jan Kochanowski Publisher, Kielce, 2011. (in Polish)

31. S. Rolewicz, Metric linear spaces, 2nd enlarged edition, PWN-Polish Scientific Publishers, Warszawa, 1984.

32. W. Szybalski, The genius of Rudolf Stefan Weigl (1883-1957), a Lvovian microbe hunter and and breeder - in memoriam, In: International Weigl Conference (11-14 Sept. 2003) at http://www.lwow.home.pl/Weigl/in-memoriam.html.

33. J.D. Tamarkin, Banach on linear operations, Bull. Amer. Math. Soc., 40 (1934), №1, 13-16.

Department of Engineering Sciences and Mathematics

Luleå University of Technology, Sweden

lech.maligranda@ltu.se

Received 25.04.2016 